\title{
Infographic. UEFA expert group 2020 statement on nutrition in elite football
}

James Collins,1,2 Ronald John Maughan,3 Mike Gleeson,4 Johann Bilsborough,5,6 Asker Jeukendrup,4,7 James P Morton,8 S M Phillips ,9 Lawrence E Armstrong,10 Louise M Burke ,11 Graeme L Close ,8Rob Duffield,5,12 Enette Larson-Meyer,13 Julien Louis,8 Daniel Medina,14 Flavia Meyer,15 Ian Rollo,4,16Jorunn Kaiander Sundgot-Borgen,17 Benjamin Wall,18 Beatriz Boullosa,19 Gregory Dupont,8,20Antonia Lizarraga,21 Peter Res,22 Mario Bizzini,23 Carlo Castagna ,24,25,26 Charlotte M Cowie,27,28Michel D’Hooghe,28,29 Hans Geyer,30 Tim Meyer,28,31 Niki Papadimitiou,32 Marc Vouillamoz,32Alan McCall 2,12,33

1Intra Performance Group, London, UK, 2Performance and Research Team, Arsenal Football Club, London, UK, 3School of Medicine, St Andrews University, St Andrews, UK, 4School of Sport, Exercise and Health Sciences, Loughborough University, Loughborough, UK, 5Faculty of Health, University of Technology, Sydney, New South Wales, Australia, 6New England Patriots, Foxboro, MA, USA, 7MySport Science, Birmingham, UK, 8Research Institute for Sport and Exercise Sciences, Liverpool John Moores University, Liverpool, UK, 9Kinesiology, McMaster University, Hamilton, Ontario, Canada, 10Human Performance Laboratory, University of Connecticut, Storrs, CT, USA, 11Mary MacKillop Institute for Health Research, Australian Catholic University, Melbourne, VA, Australia, 12Medical Department, Football Federation Australia, Sydney, NSW, Australia, 13Department of Human Nutrition, Foods and Exercise, Virginia Tech, Blacksburgh, VA, USA, 14Athlete Care and Performance, Monumental Basketball, Washington, DC, USA, 15Federal University of Rio Grande do Sul, Porto Alegre, Rio Grande do Sul, Brazil, 16PepsiCo Life Sciences, Global R\&D, Gatorade Sports, Science Institute, Birmingham, UK, 17Department of Sports Medicine, The Norwegian School of Sports Science, Oslo, Norway, 18Department 
of School of Sport and Health Sciences, College of Life and Environmental Sciences, University of Exeter, Exeter, UK, 19Mexican Sports Nutrition Federation, Mexico City, Mexico, 20Federation Francaise de Football, Paris, France, 21FC Barcelona, Barcelona, Spain, 22Dutch Olympic Team, Amsterdam, Netherlands, 23Research and Human Performance Lab, Schulthess Clinic, Zurich, Switzerland, 24University of Rome Tor Vergata, Ancona, Italy, 25Technical Department, Italian Football Federation (FIGC), Florence, Italy, 26Italian Football Referees Association, Bologna, Italy, 27Technical Directorate, Football Association, Burton upon Trent, UK, 28Medical Committee, UEFA, Nyon, Switzerland29Medical Centre of Excelence, Schulthess Clinic, Zurich, Switzerland. 30Center for Preventive Doping Research, German SportUniversity Cologne, Cologne, Germany, 31Institute of Sports and Preventive Medicine, Saarland University, Saarbruecken, Germany, 32Medical \& Anti-doping, UEFA, Nyon, Switzerland, 33Sport, Exercise and Health Sciences, School of Applied Sciences, Edinburgh Napier University, Edinburgh, UK

UEFA commissioned an expert group statement on nutrition in elite football.[1] Gathering 32 global experts in football and nutrition research and practice, the expert group statement covers nine key topics specific to football and intended to enhance the practical application of sports nutrition provision within elite football teams (male, female, junior players and referees). Given the importance of visual communication in the current sports science and medicine community, our expert group statement has been summarised into three key infographics: (1) match-day nutrition, (2) training day nutrition and (3) the 'best of the rest' that is, key take-home messages from the other topics within the statement. While methods such as infographics are a useful and potentially impactful way to engage practitioners and researchers, they do carry a risk of oversimplification and misinterpretation.[2] We therefore 
strongly advise and encourage people interested in the infographics and take-home messages to read and digest the full expert group statement to better inform if and how you decide to implement nutritional strategies in your own practice.

\section{REFERENCES}

1 Collins J, Maughan R, Gleeson M, et al. UEFA expert group 2020 statement on nutrition in elite football. Current evidence to inform practical recommendations and drive future research. Br J Sports Med 2020.

2 Impellizzeri FM. Social Media in Sport Science and Medicine: With Great Power Comes Great Responsibility. Int J Sports Physiol Perform 2018;13:253-4.

Correspondence to: Dr Alan McCall, Arsenal Performance and Research Team, Arsenal Football Club, London, UK; amccall@arsenal.co.uk

Twitter: James Collins@JamesCollinsPN, Mike Gleeson @professormichaelgleeson, Johann Bilsborough@jbils1972,Asker Jeukendrup@jeukendrup, James P Morton @JamesyMorton, S M Phillips @mackinprof, Louise M Burke@LouiseMBurke, Julien Louis@Jlnlouis, Jorunn Kaiander Sundgot-Borgen@Jorunn_SB, Charlotte M Cowie @drccowie and Alan McCall@Alan_McCall_

Contributors: AM wrote the short infographic introduction. AM and JC prepared the first draft infographics with Yann Le Meur. All authors contributed to and agreed the final versions. 
Funding: The authors have not declared a specific grant for this research from any funding agency in the public, commercial or not-for-profit sectors.

Competing interests: See COI document linked to the main paper (too large to copy paste in here).

Patient consent for publication: Not required.

Provenance and peer review: Not commissioned; internally peer reviewed. 
Infographic 1: UEFA 2020 expert group statement in elite football: Training day.

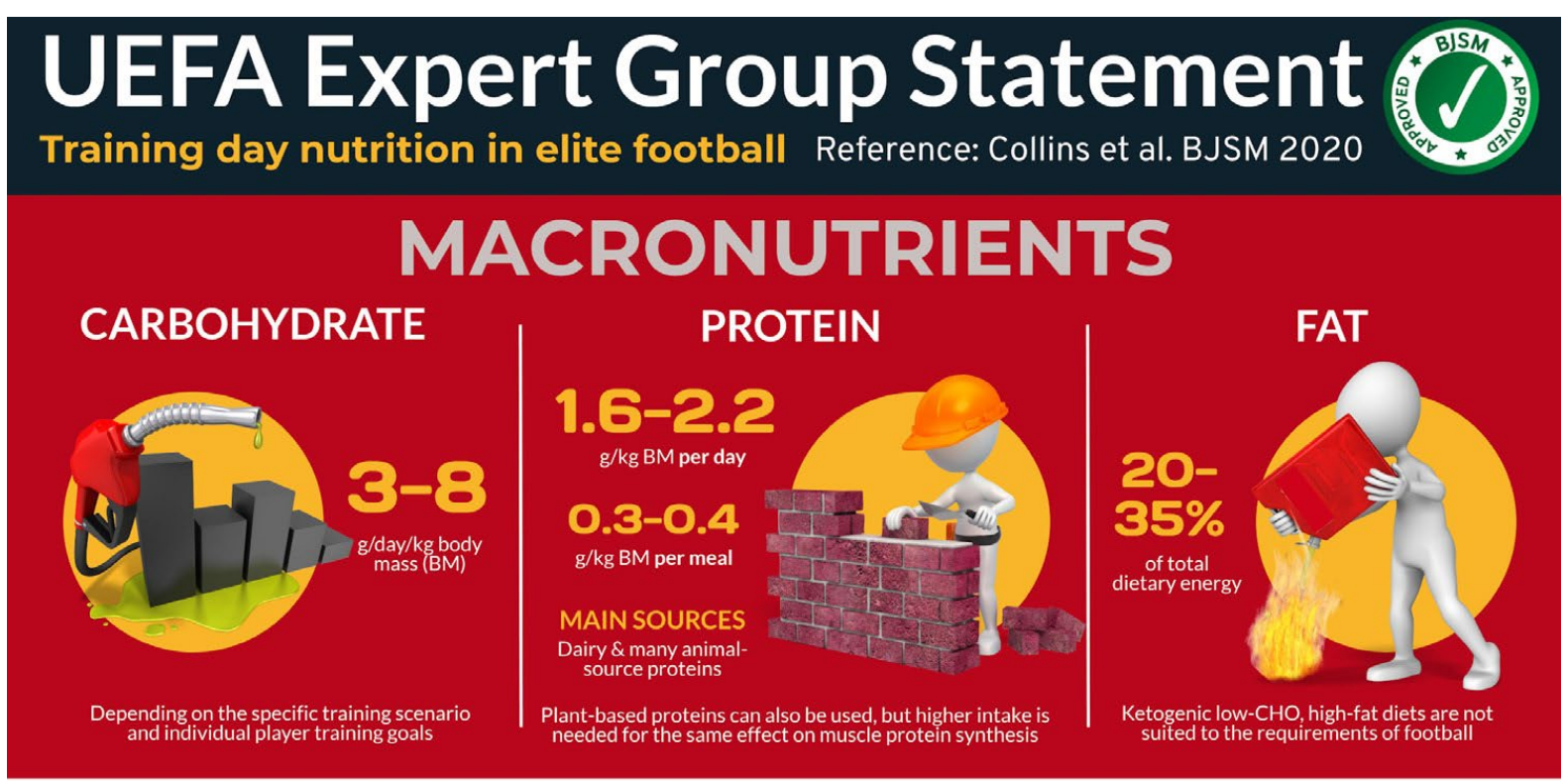

\section{KEY MICRONUTRIENTS}
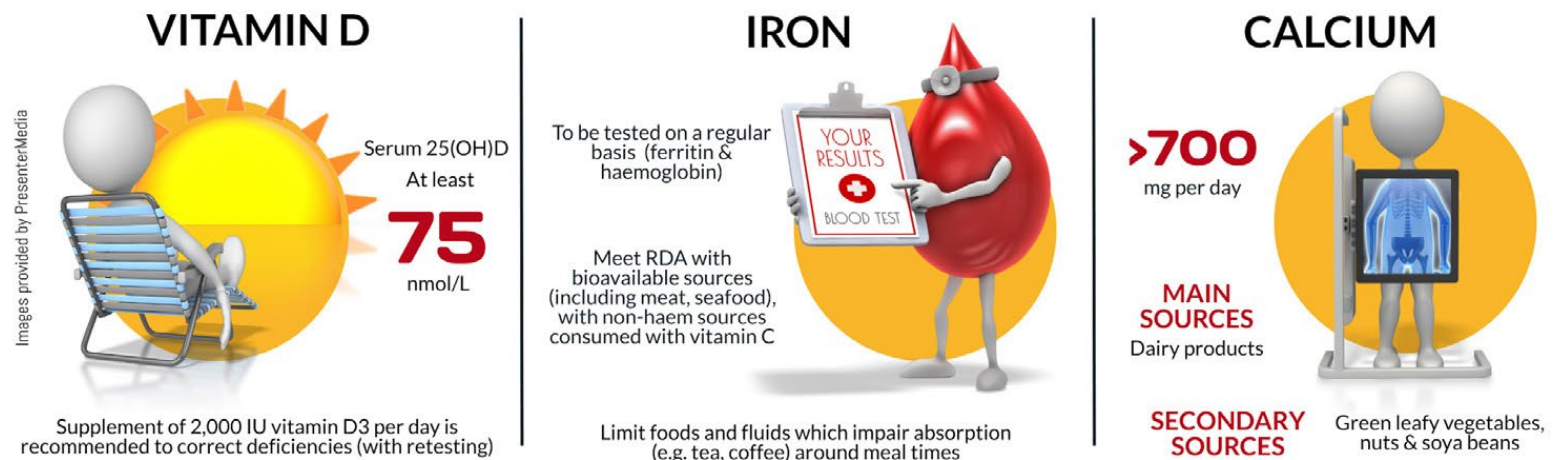

foods and fluids which impair absorptir

A varied diet is important to meet nutrient needs - Hydration is always important 
Infographic 2: UEFA 2020 expert group statement in elite football: match-day.

\section{UEFA Expert Group Statement Match day nutrition in elite football

1 On the day prior to a match (MD-1), MD and MD+1, carbohydrate $(\mathrm{CHO})$ intake should be increased to elevate muscle glycogen stores

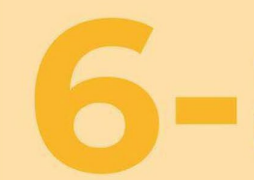

$\mathrm{g} /$ day/kg body mass (BM)
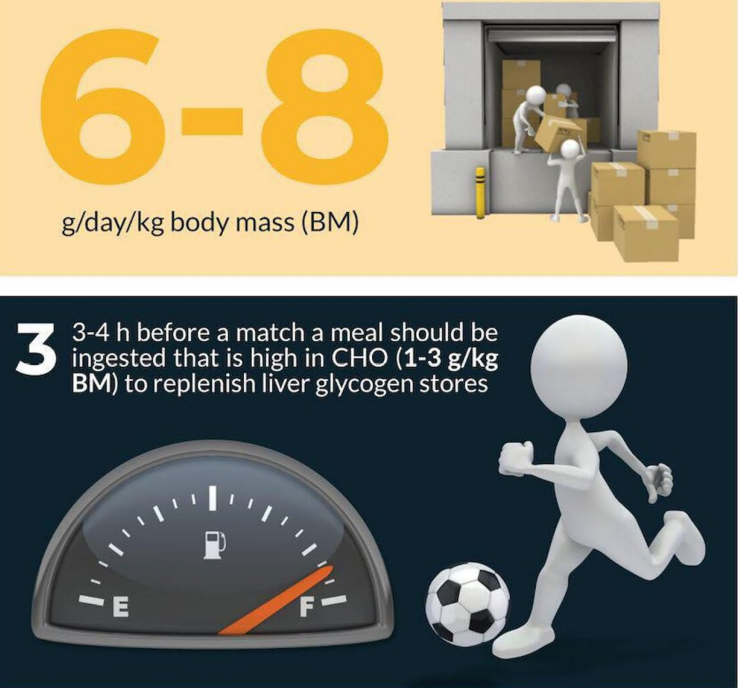

Following the warm-up and during the half-time interval an intake of around $30-60 \mathrm{~g} \mathrm{CHO}$ is recommended
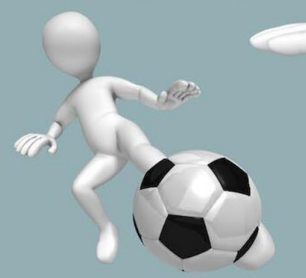

\section{0-60g CHO}

7 Supplementation with high doses of antioxidant compounds in recovery may interfere with adaptive processes within the muscle and is therefore discouraged

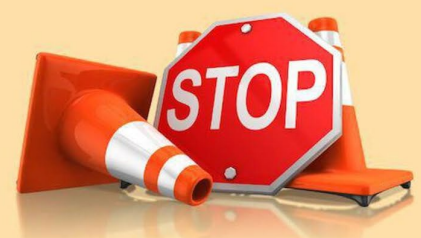
Intake is often lower than this and a conscious effort
should be made to increase CHO intake at the cost of fat intake (and possibly protein intake)
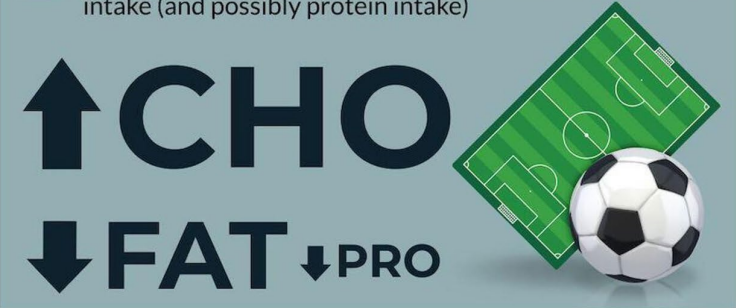

2 Start the match fully hydrated by consuming $5-7 \mathrm{ml} / \mathrm{kg}$ BM fluid 2-4 hours prior to kick-off. Drink sufficient fluids to prevent significant dehydration by developing an individualised plan based on sweat losses
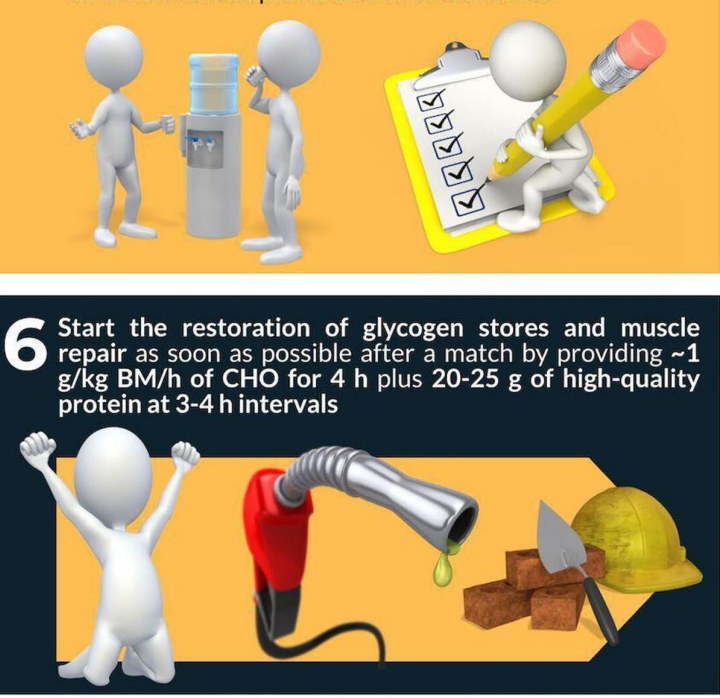

8

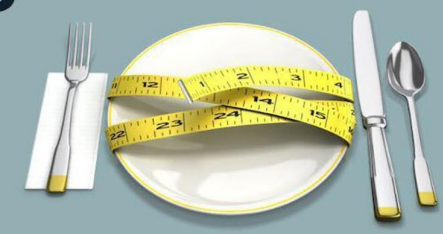

A recreational player will generally cover less distance, expend less energy and sweat less;

their nutritional needs will be somewhat lower

\section{Designed by eYLMSport Science}


Infographic 3: UEFA 2020 expert group statement in elite football: Best of the rest -8 other key take-home messages.

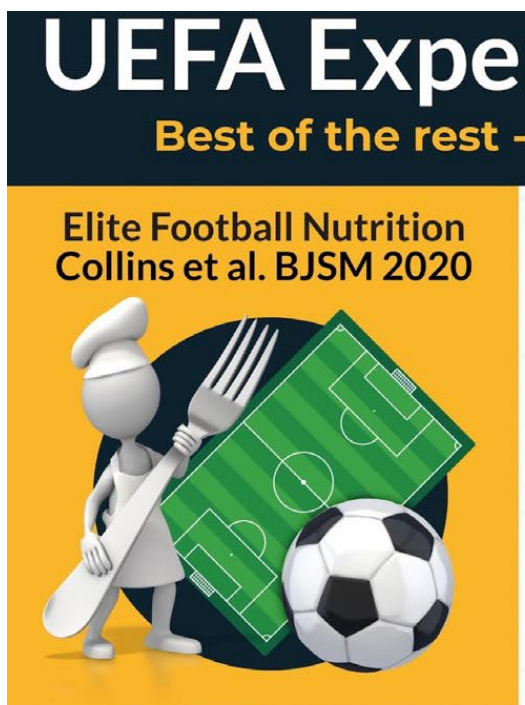

3. STRESSFUL enviRonments
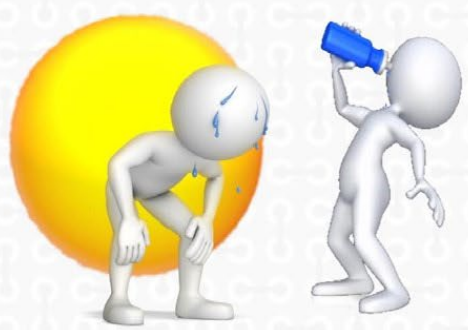

In hot environments ingesting a $2-6 \mathrm{~g} / 100 \mathrm{ml} \mathrm{CHO}$ beverage may be preferable to more concentrated CHO solutions. CHO intake should be reduced to $20-$ is prioritised over substrate delivery

\section{InJURY REHABILTITION} During the acute post-injury phase, care should be taken to maintain energy balance and protein intake and avoid micronutrient defici
wound healing and tissue repair

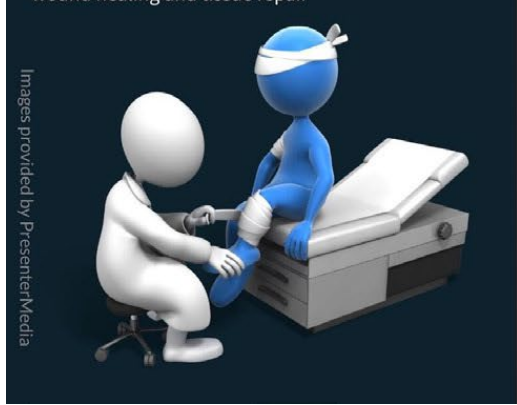

\section{STAYInG HEALTHY}

Inadequate intakes of several essential vitamins (e.g. A, D, E, B12) and minerals (e.g. iron, selenium, zinc) impair immunity but this can be prevented or
reversed by repletion. For some nutrients this may reversed by repletion.

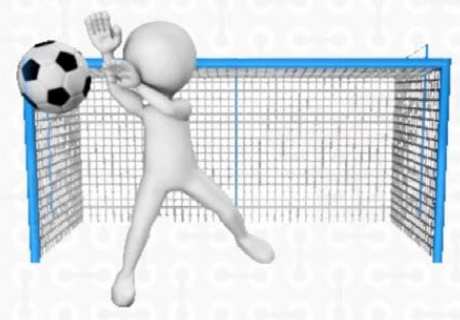

\section{CULTURAL DIVERSITY} \&. DIETARY CONSIDERATIONS

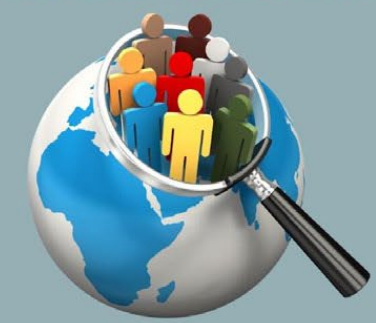

During Ramadan, players should be individually monitored with training loads adjusted accordingly, to appropriate time of day for nutritional support

\section{ReFerees}

Dietary energy intake should be adapted according to the individual training load and in days and during periods of incense training or when engaged in occupations with a high-energy demand
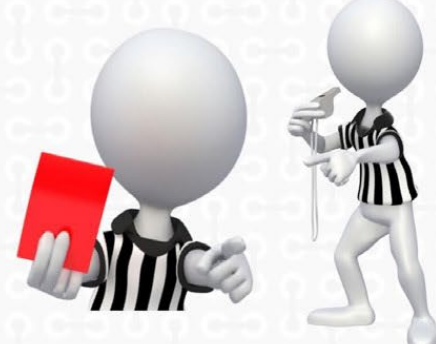

tement messages

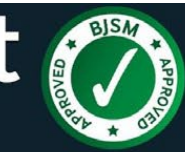

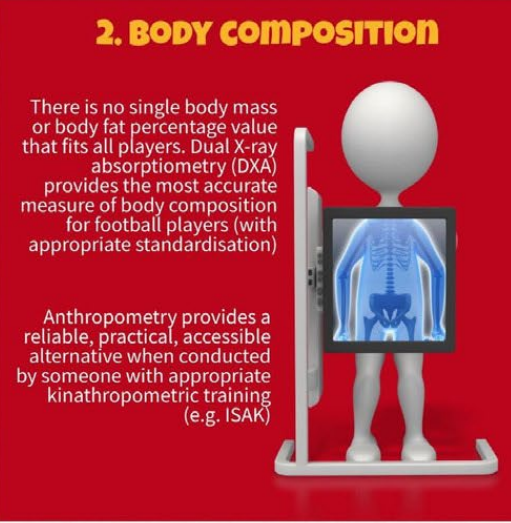

\section{DIETARY SUPPLEMENTS}

Due to the risk of a positive doping violation from the use of dietary supplements, extreme caution must be should be 'food first', with supplementation only used to meet specific health or performance objectives
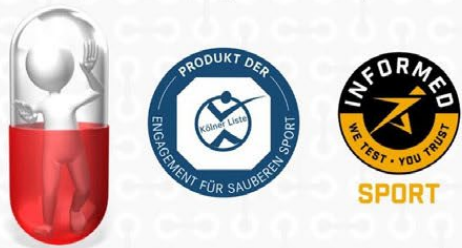

Third-party testing programmes (e.g. Kölner Liste" for Germany, Informed Sport "for the UK) will reduce the supplements

\section{JUNIOR PLAYERS}

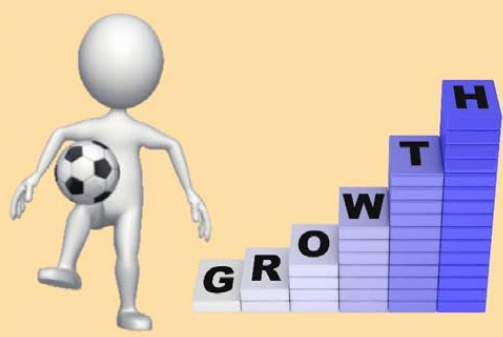

Elite junior players should be periodically evaluated in relation to their individual energy, macronutrient, micronutrient and fluid demands according to their
training/competition patterns and maturational status 